\title{
What Drives Information Dissemination in Continuous Double Auction Markets?
}

\author{
Javier Gil-Bazo \\ Universidad Carlos III \\ Dpt. of Business Administration \\ C/Madrid, 126 \\ 28903 Getafe (Madrid) Spain \\ javier.gil.bazo@uc3m.es
}

\author{
David Moreno \\ Universidad Carlos III \\ Dpt. of Business Administration \\ C/Madrid, 126 \\ 28903 Getafe (Madrid) Spain \\ jdmoreno@emp.uc3m.es
}

\author{
Mikel Tapia \\ Universidad Carlos III \\ Dpt. of Business Administration \\ C/Madrid, 126 \\ 28903 Getafe (Madrid) Spain \\ mtapia@emp.uc3m.es
}

\begin{abstract}
In this paper, we investigate further the way information disseminates from informed to uninformed traders in a market populated by heterogeneous boundedly rational agents. In order to achieve our goal, we construct a computer simulated market where only a small fraction of the population observe the risky asset's fundamental value with noise, while the rest of agents try to forecast the asset's price from past transaction data. The paper departs from previous studies in that the risky asset does not pay a dividend every period, so agents cannot learn from past transaction prices and subsequent dividend payments. Our main finding is that information can potentially disseminate in the market as long as: (1) informed investors' trades tilt transaction prices in the fundamental path direction; and (2) the median investor's expectation is very responsive to transaction prices. Otherwise, markets may display crashes or bubbles. We find that the first condition requires a minimal amount of informed investors, and is severely limited by short selling and borrowing constraints
\end{abstract}

\section{Introduction}

Electronic continuous double auction markets, where agents can submit orders to buy or sell to a computerized limit order book, are becoming the standard trading mechanism in financial markets around the world. Examples include NASDAQ Supermontage, Deutsche Börse's Xetra, Euronext or Spanish Continuous Market, as well as all Electronic Communications Networks such as Instinet or Terra Nova Trading. In other markets, as is the case of London Stock Exchange or Chicago Mercantile Exchange, electronic order-driven systems now coexist with traditional quote-driven or open-outcry trading systems.

Despite the popularity of electronic double auction financial markets, whether this system is an efficient means of price discovery or the determinants of informational efficiency in such markets, remain open questions. The theory of financial markets explain price formation in more stylized settings. In a Walrasian equilibrium, on one hand, traders base their investment decisions upon their own prior information. The equilibrium price, which equalizes demand and supply, therefore summarizes investors' heterogeneous beliefs. However, because investors do not recognize the informational content of market prices about other agents' expectations, there is no possible transfer of information from informed traders to uninformed traders and prices need not converge to the asset's intrinsic value. In a rational expectations (RE) equilibrium ${ }^{1}$, on the other hand, traders rationally update their forecasts about the future state of nature (and their beliefs about other agents' forecasts) upon observing the Walrasian equilibrium price. Agents then trade accordingly until asset prices finally reflect all available information. Private information is in this way transferred across traders. Moreover, because in equilibrium disagreement about the true price vanishes, there are no reasons to trade, and volume should be zero.

In the real world private information is not observable, so researchers have relied on experiments conducted in laboratories to test for the validity of the theory. In experimental markets with human agents and asymmetrically distributed information, Plott and Sunder (1982) and Forsythe et al. (1982) find support for the RE hypothesis: when uninformed agents coexist with informed traders, market prices converge after some time towards RE equilibrium prices $^{2}$. This evidence is considered favorable to the RE model.

In experiments with human traders, agents' strategies are beyond the researcher's control and their expectations are not observable. For this reason, computer simulated markets ${ }^{3}$ have arised as alternative laboratories to study the convergence property of the double auction trading system. In an early study, Gode and Sunder (1993) construct a simple double auction market ${ }^{4}$ where investors

\footnotetext{
See, for instance, Lucas (1972), Green (1973), Grossman and Stiglitz (1980), Grossman (1981), and Hellwig (1980, 1982).

${ }^{2}$ In other experiments, however, Forsythe and Lundholm (1990) find that both trading experience and common knowledge of agents' information structures were necessary to achieve the RE equilibrium.

${ }^{3}$ See Lebaron $(2000,2001)$ for a more detailed view of agentbased financial markets.

${ }^{4}$ In Gode and Sunder (1993) unaccepted limit orders are deleted with each transaction, unlike in a real market where limit orders stay in the book until matched by subsequent market orders or canceled by the trader who submitted them.
} 
submit random orders, and show that the market price converges to the equilibrium price as long as traders are not allowed to buy or sell at a loss. In a more recent study, Chan et al. (2001) study information dissemination in a market populated by boundedly rational investors with heterogeneous trading strategies, which include technical analysis rules and Bayesian learning. They find prices converge fast to the RE equilibrium price when investors have homogeneous preferences, but the model fails if this condition does not hold.

In this paper, we investigate further the way information transmits from informed to uninformed traders in a market populated by boundedly rational agents. In order to achieve this goal, we construct a market where only a small fraction of the population observe the risky asset's fundamental value with noise, while the rest of agents try to forecast-in different ways-the asset's price from past transaction data. Our market departs from Chan et al. (2001) in that the risky asset pays no dividend so agents cannot learn from past transaction prices and subsequent dividend payments. Consequently, convergence to the asset's fundamental price can only be attributed to private information being disseminated in the market. This distinction is important because Yang (2002) has shown that uninformed agents with no private information but endowed with neural learning capabilities can bring market prices to the RE equilibrium price

Our artificial market enables us to answer a number of pressing questions. First, can private information disseminate in a continuous double auction market where most agents never observe the realized state of nature? If the answer to the previous question is positive, how exactly does private information become impounded into prices? Finally, how do market features affect the market efficiency?

The paper's main conclusion is that private information can disseminate effectively in a continuous double auction market populated by heterogeneous boundedly rational investors. We find that, in our market, transaction prices are very close to the theoretical equilibrium price in a repeated Walrasian auction, which implies that the median investor's price expectation is very responsive to past transaction prices. It follows that convergence to the fundamental path is possible as long as informed investors' trades can affect transaction prices in the right direction. Otherwise, the market price may depart from the fundamental's price, creating crashes or bubbles. A crash, in particular, arises in our market when the price moves below the fundamental path and continues to fall despite informed investors' initial bids. Absent a budget constraint, such bids would eventually bring prices up. However, if the budget constraint becomes binding for informed investors, because of borrowing restrictions, they can no longer submit new bids to the limit order book. Only the randomness of market dynamics can then make the asset price return to the fundamental path and bring it once again under the discipline of informed traders.
The rest of the paper is organized as follows: section 2 presents the features of our artificial market; section 3 describe the design of simulations; section 4 explains the results; and, finally, section 5 concludes.

\section{A continuous double-auction artificial market}

In this section, we describe in detail the trading mechanism as well as the market's composition in terms of participating agents. At the end of the section we discuss possible equilibria.

\subsection{Market structure}

We assume that agents can store wealth in a riskless asset with zero net return (numeraire) and a risky asset. For the risky asset, we model a decentralized trading mechanism with no market maker, where orders are submitted by any investor and matched automatically. More specifically, our market is based in Chan et al. (2001).

We have simulated 1,000 trading periods. Each trading period (that represents one day) consists of 5 rounds of trading, which implies that each agent is granted the opportunity to trade a maximum of 5 times in a trading period. The event of one agent participating in a given round is random with probability $0.7^{5}$. Participating agents are sorted randomly ${ }^{6}$. When an agent's turn arrives, he may submit a limit order, i.e., he may quote a price to buy (bid) or sell (ask) one unit of the risky asset. Alternatively, the agent may introduce a market order, which means that he may buy one unit of the risky asset at the best ask price or sell at the best bid price. As in Chan et al. (2001) or Chiarella and Iori (2002) we restrict the order size to one unit of the risky asset in order to limit the dimension of the investor's problem.

At the time of submitting an order, the agent must satisfy two different budget constraints. First, he cannot submit market orders which imply short-selling the risky asset or borrowing. Second, he cannot submit a limit order such that if all his limit orders were matched at some point in the future, he would have to short sell or borrow.

Also agents can cancel suboptimal limit orders every time they go to the market. These orders are defined as those that would result in a loss given the agent's new beliefs about the risky asset's price.

Finally, agents' orders to buy (sell) are rounded downwards (upwards) in order to comply with the exchange's tick size requirements. In particular, we have chosen to set the tick size equal to 0.001 dollars.

\subsection{Fundamental price}

We asume that the risky asset's fundamental price dynamics is governed by a geometric Brownian motion:

\footnotetext{
${ }^{5}$ It is based on the idea that, in real financial markets, agents do not trade everytime: even active agents usually trade a few times in a trading session.

${ }^{6}$ A permutation of agents is randomly sampled from all possible permutations according to a uniform discrete distribution.
} 


$$
d P_{f, t}=\mu P_{f, t} d t+\sigma P_{f, t} d W,
$$

where $P_{f, t}$ denotes the risky asset's fundamental price at time $\mathrm{t}$ and $W_{t}$ a standard Brownian motion. Under this process, the fundamental price is conditionally lognormally distributed:

$$
\ln P_{f, t+\Delta} \sim \phi\left(\ln P_{f, t}+\left(\mu-\frac{\sigma^{2}}{2}\right) \Delta, \sigma \sqrt{\Delta}\right)
$$

where $\Delta$ is the time interval between two trading periods (we set $\Delta=250^{-1}$ ) and $\phi$ denotes the normal density function. The continuously compounded fundamental return, computed as the difference in logs, is normally distributed, serially independent and has constant variance.

\subsection{Agents and trading}

All agents are risk neutral and myopic. Their objective function is therefore the expected value of their wealth at the end of each trading period. In order to form this expectation, i-th agent forecasts the risky asset's price at the end of the current trading period, $P_{t}^{i}$, and buys as long as the best ask price is at least $S$ dollars below his forecast. Similarly, he sells as long as the best bid price is at least $S$ dollars above his forecast. This assumption is necessary to incorporate explicit transaction costs such as broker commission or fees: investors will trade only if the expected profit from trading is high enough to offset the cost of trading. Note, however, that a higher value of $S$ will decrease the volume/frequency of trading. In our simulations, the exact value of $S$ for each agent at each round is a realization from a uniform distribution.

The agent can also submit a new bid $\left(P_{t}^{i}-S\right)$ or ask $\left(P_{t}^{i}+S\right)$. The agent's limit order is subsequently added to the limit order book in the corresponding position. Table 1 displays the agents' decision process.

Agents differ from each other in the way they obtain their forecast of the risky asset's price. In our market we consider four different classes of agents:

i) Zero Intelligence (ZI) agents. In our market, ZI agents serve as liquidity providers, since they introduce discrepancy in the risky asset's valuation. Their prediction for the risky asset's price is a realization of a random variable which is uniformly distributed around the last transaction price:

$$
P_{t}^{i} \sim U\left(0.9 P_{\tau}, 1.1 P_{\tau}\right)
$$

where $\tau$ denotes the last time the risky asset was traded. This way of modelling ZI agents' behavior depart from that of Gode and Sunder (1993), since in our market ZI agents modify their prediction with every transaction. Consequently, if the market where exclusively populated with ZI agents we would not expect convergence to the "equilibrium price" since a high (low) transaction price would shift expectations for all agents upwards (downwards). Moreover, they enable us to assess the effect of informed-based trading on uninformed traders' wealth.

Table 1. Order generation procedures.

\begin{tabular}{cc}
\hline Scenario & Order \\
\hline Case 1:There is at least one ask price and one bid price \\
in the limit order book
\end{tabular}

ii) Informed agents. They observe the risky asset's fundamental price plus some noise. Their forecast of the asset's price is the fundamental price:

$$
P_{t}^{i} \sim U\left(0.99 P_{f, t}, 1.01 P_{f, t}\right)
$$

We could think of informed agents as fundamentalist traders (more noise) or as insider traders (less noise). To the extent that informed traders' orders drive market prices towards the risky asset's fundamental value, prices become informationally efficient.

iii) $A N N$ agents. These investors use an nonlinear model (Artificial Neural NetWorks (ANN)) to forecast next period's return. Artificial Neural Networks have been usually considered as complex models inspired in the structure of the brain. ANNs inherit three basic characteristics of the biological neurons: they are intrinsically parallel; they provide nonlinear responses to stimulus; and they process the information through several layers of interconnected neurons. One of the main characteristics of ANNs is their capacity to "learn" and "generalize" using real data, that is, an ANN learns the relationship between a set of inputs and their

\footnotetext{
${ }^{7}$ The lowest ask prevailing in the limit order book when the agent takes his decision is denoted by $a$ and the highest bid is denoted by $b$.
} 
corresponding outputs. An ANN is composed of a number of processing units which are hierarchically organized in layers. The input layer consists of a set of nodes that receive the information from the outside world. The hidden layer processes the information while the output layer sends the signal to the outside ${ }^{8}$. The most widely used structure is that of a feedforward neural net in which the information is hierarchically processed in a single way from the input layer to the output through the hidden layer(s). The units are connected through a synaptic weight which determines quantitatively the influence of one unit on the other. Specifically, the ANN agents we use a feedforward neural net with a unique hidden layer", " $h$ " input units, and a unique unit in the output layer to form their expectation about next period's return. It is important to highligh that the net is not fix during a simulation, is trained each " $\mathrm{m}$ " trading periods (More specifically, we select the parameters, $h=10, \mathrm{~m}=$ 50 , and the number of epochs used in the training of nets is 200). Therefore, as the market becomes more efficient, the ANN agents are capable of training the net in a more efficient way, and therefore the ANN agents evolve towards more efficient agents.

iv). Technical Analysts (TA). These agents attempt to identify trends in price series. In particular, they compute the average close price of last $s$ trading periods and the average close price of last 1 periods, where $s$ is either 1,2 or 5 periods with equal probability and 1 can take the following values: 50,150 or 200 , also with equal probability. If the short moving average is higher than the long moving average the TA will think the market is bullish and will want to buy the risky asset. Otherwise, he will sell ${ }^{10}$. TA's actions therefore differ slightly from those of the rest of agents. In particular, in a bullish market, a TA will buy at the prevailing ask price, a, if there is at least one ask price with $P_{t}^{i}>a+S$, where $P_{t}^{i}$ is taken to be price of the last transaction. Otherwise, they will submit a limit order to buy with bid equals to $P_{t}^{i}-\mathrm{S}$. Analogously, in a bearish market, TAs will sell at the prevailing bid price, $b$, if there is at least one bid price with $P_{t}^{i}<b-S$ and will submit a limit order to sell with ask equal to $P_{t}^{i}+\mathrm{S}$, otherwise.

At the beginning of each simulation, each agent receives an identical endowment consisting of 3,000 dollars and 30 units of the risky asset. Since TAs and ANN agents require a minimum number of transactions before they start to trade, wealth is reinitialized again when all agents

\footnotetext{
${ }^{8}$ Kuan and White (1994) provide an introduction to ANNs in an econometric context, showing that these models are, in fact, quite familiar to the econometrician, see it for a more detailed description.

${ }^{9}$ Hornik et al. (1989) showed that an ANN with a single hidden layer with enough hidden logistic units and linear outputs can approximate arbitrarily well any measurable function.

${ }^{10}$ In future extensions, TA might use a genetic algorithm to select among competing forecast rules as in Arthur et al. (1996) or Lettau (1997).
}

operate simultaneously. For this reason, in the first 200 periods only informed agents and ZI agents participate and we do not take into account these results in our futher analysis.

\subsection{Equilibrium}

Given the risk neutral assumption and the restriction to buying or selling one unit of the asset, in the absence of explicit transaction costs, the Walrasian equilibrium price roughly corresponds to the sample median of individuals' expectations. To see this point assume zero explicit transaction costs and no budget constraint. If we let $F_{N}(\cdot)$ and $\mathrm{N}$ denote the empirical distribution of $P_{i}$ and the number of agents, respectively, the demand function for the risky asset then equals $\mathrm{Q}^{\mathrm{D}}(P)=\mathrm{N} \cdot\left(1-\mathrm{F}_{\mathrm{N}}(P)\right)$ whereas the supply function is given by $\mathrm{Q}^{\mathrm{S}}(P)=\mathrm{N} \cdot \mathrm{F}_{\mathrm{N}}(P)$. The market-clearing price is such that:

$$
\left(1-\mathrm{F}_{\mathrm{N}}(P)\right)=\mathrm{F}_{\mathrm{N}}(P) \text {, }
$$

which is exactly the sample median price expectation. Introducing a fixed explicit transaction cost, $S$, changes the above condition to $\left(1-\mathrm{F}_{\mathrm{N}}(P+S)\right)=\mathrm{F}_{\mathrm{N}}(P-S)$. The equilibrium price, $P^{*}$, is therefore not affected as long as $\mathrm{F}_{\mathrm{N}}\left(P^{*}+S\right)-\mathrm{F}_{\mathrm{N}}\left(P^{*}\right)=\mathrm{F}_{\mathrm{N}}\left(P^{*}\right)-\mathrm{F}_{\mathrm{N}}\left(P^{*}-S\right)$, but the number of units exchanged is necessarily lower.

The noisy RE equilibrium price results from updating a prior distribution about the fundamental price upon observing price signals received by all informed traders. For a sufficiently high number of signals or for sufficiently precise signals, this noisy RE equilibrium price is close to the fundamental price.

Note that in this market, convergence to the RE price can be achieved as long as informed investors influence the Walrasian equilibrium price, since the rest of investors will react to observed price changes.

\section{Simulation design}

In order to analyze the sensitivity of market's efficiency to market parameters we have simulated 10 paths of fundamental values according to (1) with a different $\mu$ for each path (uniformly distributed between $+/-5 \%$ ), and $P_{f, 0}=100$. The reason why we let $\mu$ change is to ensure that results do not depend on a specific market trend. Next, for each fundamental path, we have simulated a total of 1,000 trading periods, changing one of the market parameters at a time ${ }^{11}$. More specifically, we have considered the parameter sets shown in Table 2 .

\footnotetext{
${ }^{11}$ Since each trading period contains 5 trading rounds, each simulation consists of 5,000 trading rounds.
} 
Table 2. Sensitivity Analysis ${ }^{12}$

\begin{tabular}{|c|c|c|c|c|c|c|}
\hline \multirow{2}{*}{ Market } & \multicolumn{3}{|c|}{$\begin{array}{c}\text { Number of } \\
\text { Agents }\end{array}$} & \multicolumn{2}{|c|}{ Budget } & \multirow{2}{*}{$\begin{array}{c}\text { Explicit } \\
\text { Transaction } \\
\text { Costs (S) }\end{array}$} \\
\hline & $\begin{array}{l}\text { Infor- } \\
\text { med }\end{array}$ & ANN & TA & Cash & $\begin{array}{l}\text { Asset } \\
\text { Units } \\
\end{array}$ & \\
\hline Benchmark & 40 & 10 & 40 & 3,000 & 30 & $\mathrm{U}(\mathbf{0 , 2 )}$ \\
\hline Market 1 & 20 & 10 & 40 & 3,000 & 30 & $\mathrm{U}(0,2)$ \\
\hline Market 2 & 40 & 0 & 40 & 3,000 & 30 & $\mathrm{U}(0,2)$ \\
\hline Market 3 & 40 & 10 & 0 & 3,000 & 30 & $\mathrm{U}(0,2)$ \\
\hline Market 4 & 40 & 10 & 40 & $\infty$ & $\infty$ & $\mathrm{U}(0,2)$ \\
\hline Market 5 & 40 & 10 & 40 & 3,000 & 30 & $\mathrm{U}(0,2.5)$ \\
\hline
\end{tabular}

To study convergence of the price dynamics to the fundamental path, we compute the following measures from Theissen (2000):

a) Mean Absolute Error

It is the average of absolute deviations of the transaction close price from the fundamental price.

$M A E=\frac{1}{T} \sum_{t=1}^{T} P_{t}-P_{t}^{f}$

b) Mean Relative Error

It enables comparisons across different paths.

$M R E=\frac{1}{T} \sum_{t=1}^{T} \frac{P_{t}-P_{t}^{f}}{P_{t}^{f}}$

c) Root Mean Squared Error

This measure weights extreme relative errors more heavily:

$$
R M S E=\sqrt{\frac{1}{T} \sum_{t=1}^{T}\left(\frac{P_{t}-P_{t}^{f}}{P_{t}^{f}}\right)^{2}}
$$

\section{Results}

Table 3 displays the average descriptive statistics of endof-period returns in all five markets. The table shows that microstructure noise in our benchmark market accounts for more than half the standard deviation of market returns, which increases from $10 \%$ in the fundamental series to $25.13 \%$ in market terms. Moreover, the Value at Risk of the fundamental path is multiplied by 4 . Interestingly, market returns in our computer simulated are characterized by excess kurtosis and non-normality in 6 of the 10 simulated series. Finally, the return distribution is negatively skewed. Our benchmark market therefore captures stylized facts of real financial markets ${ }^{13}$. When the number of informed agents is halved (Market 1), price dynamics depart even more from the fundamental distribution: volatility increases from

\footnotetext{
${ }^{12}$ The number of ZI agents is 120 in all markets and the standard deviation of the fundamental prices is fixed to $10 \%$ for all experiments.

${ }^{13}$ Although the results are not shown in the paper, we must note that as in real financial markets we also found evidence of volatility clustering in our market.
}

$25.13 \%$ to $65.87 \%$, negative skewness, kurtosis, and Value at Risk also rise significantly, and, finally, normality is rejected in all simulations. Table 4 displays measures of efficiency for all markets: convergence to the fundamental price drops dramatically in Market 1 with respect to the benchmark market. To understand these results, we consider a single fundamental path and analyze price dynamics in the benchmark market and Market 1.

Table 3. Descriptive Statistics for returns.

Retum is the average mean return in percentage for each market and for the fundamental prices. Std. Dev. means the average mean standard deviation in percentage. Skw shows the mean skewness. Kur is the kurtosis. VaR show the minimum price decrease with a $99 \%$ probability, and the last column (Reject. norm) shows the number of times that the null hipothesis of normality is rejected using the Jarque-Bera test at $10 \%$ of significance.

\begin{tabular}{lrlrrrrr}
\hline & $\begin{array}{l}\text { Return } \\
(\%)\end{array}$ & $\begin{array}{l}\text { Std. } \\
\text { Dev. } \\
(\%)\end{array}$ & Skw & Kur & VaR & \multicolumn{2}{l}{$\begin{array}{l}\text { Reject. } \\
\text { norm }\end{array}$} \\
\hline Fundamen- & -0.83 & 9.97 & 0.016 & 2.9 & 2.02 & 0 \\
tal & -2.09 & 25.13 & -0.009 & 7.1 & 8.46 & 6 \\
Benchmark & 1.09 & 65.87 & -0.15 & 17.0 & 31.70 & 10 \\
Market 1 & -0.67 & 34.66 & -0.44 & 21.6 & 17.37 & 9 \\
Market 2 & -0.27 & 27.85 & 0.03 & 4.0 & 6.43 & 4 \\
Market 3 & -0.49 & 18.09 & -0.22 & 8.7 & 7.04 & 8 \\
Market 4 & -0.29 & 21.92 & 0.29 & 7.8 & 4.58 & 1 \\
Market 5 & & & & & & \\
\hline
\end{tabular}

Table 4. Informational efficiency for all simulations

\begin{tabular}{lccc}
\hline & MAE & MRE & RMSE \\
\hline Benchmark & 3.63 & $3.17 \%$ & $5.96 \%$ \\
Market 1 & 17.54 & $17.24 \%$ & $28.02 \%$ \\
Market 2 & 2.00 & $2.04 \%$ & $4.68 \%$ \\
Market 3 & 1.03 & $1.04 \%$ & $1.32 \%$ \\
Market 4 & 0.81 & $0.82 \%$ & $1.13 \%$ \\
Market 5 & 3.54 & $3.09 \%$ & $5.84 \%$ \\
\hline
\end{tabular}

Figure 1 shows how close transaction prices are to fundamental prices in the benchmark market. This Figure is in contrast to Figure 2 that corresponds to Market 1. First, the high volatility of returns is apparent from the bottom panel (returns) of Figures 1 and 2 in all periods. Informed investors not only ensure convergence to price fundamentals, but also reduce randomnes in transaction prices as suggested by Table 3 . The top panel (prices), on the other hand helps explain the poor efficiency results of Table 4. While transaction prices in Market 1 tend to track the fundamental path in most periods, from period 200 to period 350 , the market experiences a crash. This crash starts with a sharp decline in the asset's price followed by periods of stability, and finally, a quick return to the fundamental path that is not abandoned again. Finally, the 
medium panel shows that trade volume peaks when prices fall and rise, and remains relatively low in between.

In order to understand the crash in Market 1, we look at the evolution of agents' average positions per investor class, which are shown in Figure 3.

\section{Figure 1. Price dynamics in the benchmark market.}

The red and dotted line corresponds to transaction prices/returns and the solid line corresponds to fundamental prices/returns.

FUNDAMENTAL PRICE AND MARKET PRICE AT THE END OF EACH PERIOD
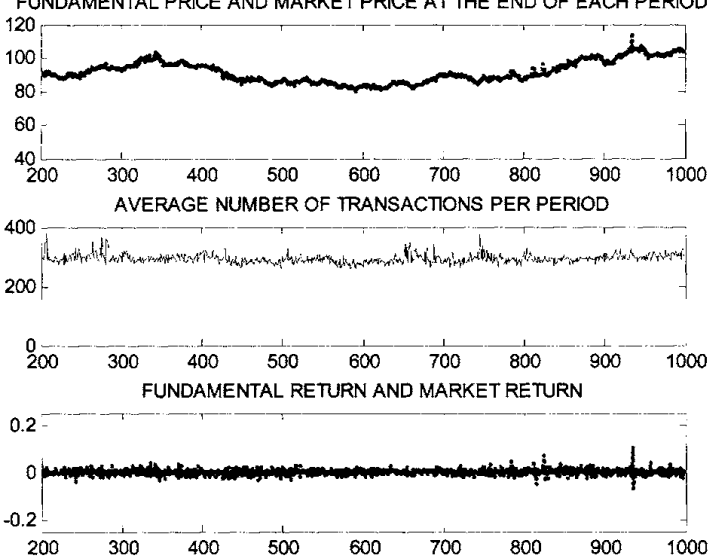

Figure 2. Price dynamics in Market 1.

The red and dotted line corresponds to transaction prices/returns and the solid line corresponds to fundamental prices/returns.
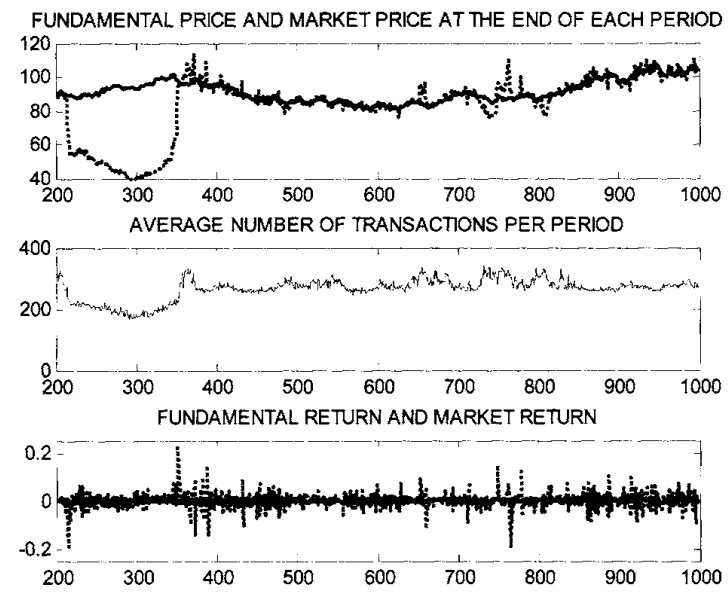

Figure 3 shows that as Technical Analysts sell their positions, the price falls below its fundamental value. Informed investors then increase their positions in the asset. By doing so, they run out of cash, and since borrowing is not permitted, they cannot submit new bids to the system. Because TA are also constrained by short selling restrictions, they cannot continue selling and prices stabilize. Towards period 300 , only ANN agents and $\mathrm{ZI}$ agents can trade. As prices eventually rise above their recent mean, TA start to buy from ANN and ZI agents, and prices start to rise again. Around period 350 , prices have already reached the fundamental path and keep rising, so informed traders intervene again selling the asset. This time, however, their orders manage to bring prices down to the fundamental path. Since market price stay close to the fundamental price after the crash, informed agents enjoy an informational advantage that enables them to beat other agents in the long run. Informed agents must therefore create a critical mass for information to disseminate in the market.

Figure 3. Agents' average positions per investor category in Market 1.

This table shows the agent's position in cash, risk asset and also the total wealth in each trading period. The thick solid, thin solid, dashed and dotted lines correspond to informed investors, zero intelligence agents, technical analysts and ANN agents, respectively.
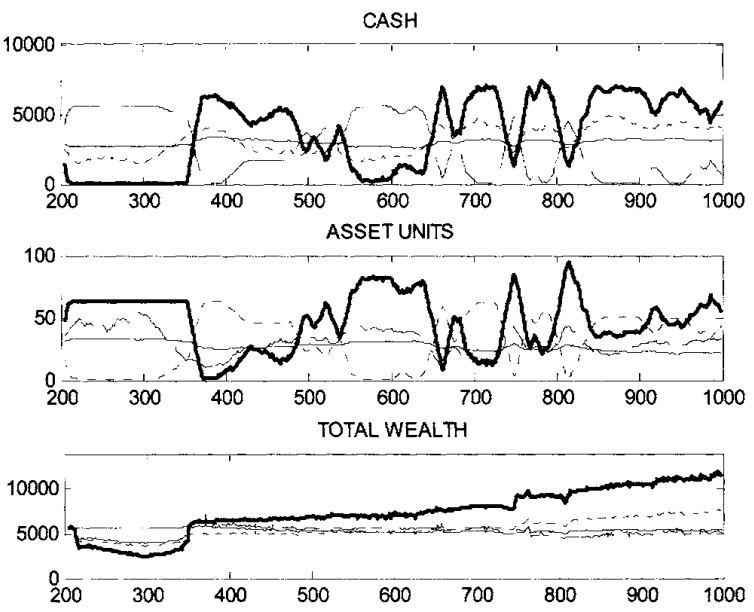

In Markets 2 and 3, we investigate the effect of a reduction in the number of ANN and TA, respectively. Table 3 suggests that reducing the number of ANN agents has an affect on market dynamics similar to the effect of reducing the number of informed agents: volatility, Value at Risk, negative skewness and kurtosis increase with respect to the benchmark. Eliminating TA from the market, however, affects market dynamics only slightly, although Value at Risk, kurtosis and nonnormality reduce slightly, and skewness becomes positive. Finally, reducing the number of ANN agents and, especially, TA has a clear positive effect on efficiency. These results imply that TA contribute to nonnormality in returns while ANN agents have the opposite effect. The presence of both, however, reduces the relative weight of informed agents, and therefore their ability to influence prices.

Since information dissemination appears to be limited by the presence of a budget constraint, it is an interesting exercise to investigate how the market behaves when such constraint is never binding. As we can see in Table 3, Market 4 is characterized by lower volatily and Value at Risk than the benchmark market, although returns display more kurtosis and negative skewness. With regards to price dissemination, as expected, Table 4 shows that prices in this market capture private information remarkably well. Clearly, when informed investors are 
not constrained by their budget, their ability to influence prices is much stronger. Non-normality of returns, which appears to be related with the presence of TA also increases, since these agents are also free from their budget constraint.

Finally, we study how a specific feature of the market microstructure, explicit transaction costs, affect market prices. When the upper bound of $S$ is raised to 2.5 , according to Table 3 (Market 5), volatility in returns and, most notably, VaR reduce with respect to the benchmark market. Normality in this market is only rejected in 3 out of the 10 simulations. Although not shown in the paper for the sake of brevity, our analysis of the limit order book suggests that higher explicit transaction costs make trading less likely and increases the depth of the limit order book. The natural consequence is a reduction in the sensitivity of market prices to minor shifts in investors' expectations, and hence in volatility. Moreover, this reduction in volatility does not come at the expense of increased inefficiency: information dissemination actually improves according to Table 4 .

The analysis of Market 1 has suggested that when informed investors are not sufficient in number, the budget constraint limits the ability of market prices to reflect private information. But, how do market prices become informationally efficient in the first place? To gain further insight, we consider the same fundamental path as in the previous examples, and compute the median price expectation across all agents in each period. As explained above, in our market this price roughly corresponds to the equilibrium price in a Walrasian auction, but because we use all of investors' expectations in each period, it should be interpreted as the median price after a series of repeated auctions when agents are reactive to market information. We then compute the correlation matrix for the market price, the fundamental price and the Walrasian price. We split each series Results are displayed in Tables 5 and 6.

\section{Table 5. Price correlations for a single fundamental path. Periods 250-625.}

This table shows the correlation coefficient between market prices $\left(\mathrm{P}_{t}\right)$, fundamental prices $\left(\mathrm{P}_{\mathrm{f}}\right)$ and the Walrasian price $\left(\mathrm{P}_{\mathrm{W}_{\mathrm{a}}}\right)$.

\begin{tabular}{lccc}
\hline & $\mathrm{P}_{\mathrm{t}}, \mathrm{P}_{\mathrm{f}}$ & $\mathrm{P}_{\mathrm{t}}, \mathrm{P}_{\mathrm{Wa}}$ & $\mathrm{P}_{\mathrm{f}}, \mathrm{P}_{\mathrm{Wa}}$ \\
\hline Benchmark & 0.986 & 0.987 & 0.997 \\
Market 1 & -0.355 & 0.993 & -0.367 \\
Market 2 & 0.980 & 0.981 & 0.998 \\
Market 3 & 0.988 & 0.988 & 1 \\
Market 4 & 0.989 & 0.993 & 0.994 \\
Market 5 & 0.989 & 0.989 & 0.998 \\
\hline
\end{tabular}

Table 6. Price correlations for a single fundamental path. Periods 626-1000.

This table shows the correlation coefficient between market prices $\left(\mathrm{P}_{t}\right)$, fundamental prices $\left(\mathrm{P}_{\mathrm{f}}\right)$ and the Walrasian price $\left(\mathrm{P}_{\mathrm{Wa}}\right)$.

\begin{tabular}{lccc}
\hline & $\mathrm{P}_{\mathrm{t}}, \mathrm{P}_{\mathrm{f}}$ & $\mathrm{P}_{\mathrm{t}}, \mathrm{P}_{\mathrm{Wa}}$ & $\mathrm{P}_{\mathrm{f}}, \mathrm{P}_{\mathrm{Wa}}$ \\
\hline Benchmark & 0.987 & 0.987 & 0.998 \\
Market 1 & 0.873 & 0.951 & 0.890 \\
Market 2 & 0.985 & 0.986 & 0.998 \\
Market 3 & 0.991 & 0.991 & 1 \\
Market 4 & 0.993 & 0.995 & 0.997 \\
Market 5 & 0.992 & 0.992 & 0.999 \\
\hline
\end{tabular}

The first column from Tables 5 and 6 confirms the conclusion that market prices in our continuous double auction are generally very responsive to changes in informed investors' expectations. In the second part of the series, when informed investors only account for $10 \%$ of total traders (Market 1), the correlation between the fundamental path and transaction prices is $87.33 \%$. Of course, in this market there is a high risk of departures from the fundamental path as becomes apparent from the low correlation between market prices and true prices in the first part of the sample

Interestingly, Tables 5 and 6 provide an explanation for information dissemination in the double auction market. The highest correlations are those between the market price and the Walrasian price. This implies that the market's median expectation in this market reacts fast to past transaction prices. Consequently, when informed investors' orders are able to shift transaction prices in the "right" direction, subsequent convergence of transaction prices to the fundamental price is almost assured. The main lesson from Tables 5 and 6 is that boundedly rational investors' ad hoc responses to market prices appear "as though" investors rationally update their beliefs about the true asset price which in turn leads to a RE-like equilibrium.

Finally, all but one correlation coefficient is marginally higher in Table 6 than its counterpart in Table 5. In other words, as time passes, prices become more efficient. This effect, however, cannot be attributed to learning, since it is present even when there are no ANN agents in the market. We conjecture that the higher wealth accumulated by informed investors in the second part of the series, diminishes the probability of their budget constraint becoming binding, and hence strengthens their capacity to influence prices.

\section{Summary and conclusions}

The idea that private information can disseminate well in continuous double auction markets has found support both in experiments with humans and with computational agents. The exact mechanism through which such transfer 
of information is possible, however, deserves a further look. This paper is an attempt to shed light on this issue with important implications for both academics and market structure designers.

Our main finding is that when investors respond, even in mechanical ways, to transaction prices, minor shifts in these prices can potentially alter the median investor's beliefs towards the intrinsic asset value. If informed traders are a sufficient fraction of total investor population, their trades have the potential to bring prices to the fundamental path. This ability, however, is limited by borrowing and short-selling restrictions, which prevents them from bidding up prices in a stock market crash or offering the asset when it is highly overvalued. The presence of other investors, or increased explicit transaction costs, introduces noise in the system and has interesting effects on market dynamics, but does not alter the main conclusions regarding information dissemination.

The idea that short sale or borrowing constraints can prevent information or opinions from being expressed in stock prices is not new. Miller (1977) or Diamond and Verrechia (1987) models express this point formally. Our paper shows that the same perverse effect of short selling and borrowing constraints is present in more complex markets populated by heterogenous boundedly rational investors. Moreover, our results show that the same constraints prevent rumors or techical analyst from driving asset prices from their intrinsic values forever. This benefit, however, is more than outweighted by the cost.

\section{Bibliography}

Arthur W.B., Holland J.H., LeBaron B., Palmer R.G., and Tayler P. (1996) "Asset Pricing Under Endogenous Expectations in an Artificial Stock Market", Santa Fe Institute Working Paper 96-12-093.

Chan, N. T., B. D. LeBaron, T. Poggio, and A. W. Lo. (2001) "Agent-Based Models of Financial Markets: A Comparison with Experimental Markets", MIT Sloan Working Paper No. 4195-01.

Chiarella, C. and G. Iori. (2002) "A Simulation Analysis of the Microstructure of Double Auction Markets", Quantitative Finance, 2, 346-353

Diamond, D. W. and R. E. Verrecchia. (1987) "Constraints On Short-Selling And Asset Price Adjustment To Private Information," Journal of Financial Economics, v18(2), 277-312.

Forsythe, R. and R. Lundholm. (1990) "Information Aggregation N An Experimental Market," Econometrica, v58(2), 309-348.

Forsythe, R., T. R. Palfrey and C. R. Plott. (1982) "Asset Valuation In An Experimental Market," Econometrica, v50(3), 537-568.

Gode, D. K. and Sunder, S. (1993) "Allocative Efficiency of Markets with Zero Intelligence Traders", Journal of Political Economy 101, 119-137.
Green, Jerry R. (1973) "Information, Efficiency and Equilibrium." Discussion Paper no. 284, Harvard Univ., Harvard Inst. Econ. Res., March.

Grossman, S. J. (1981) "An Introduction to the Theory of Rational Expectations under Asymmetric Information," Review of Economic Studies, 48, 541-559.

Grossman, S. J., and J. E. Stiglitz (1980) "On the Impossibility of Informationally Efficient Markets," American Economic Review, 70, 393-408.

Hellwig, M. E. (1980) "On the Aggregation of Information in Competitive Markets," Journal of Economic Theory, 22,477-498.

Hellwig, M. E. (1982) "Rational Expectations Equilibrium with Conditioning on Past Prices: A Mean Variance Example," Journal of Economic Theory, 26, 279-312.

Hornik, K., M. Stinchcombe and H. White, (1989) "Multilayer feedforward networks are universal approximators", Neural Networks, 2, 359-366

Kuan, C.M. and H. White (1994) "Artificial Neural Networks: an Econometric Perspective," Econometric Reviews, 13, 1-91.

LeBaron, B. (2000) "Agent-Based Computational Finance: Suggested Readings and Early Research", Journal of Economic Dynamics and Control, 24, 679702.

LeBaron, B. (2001) "A Builder's Guide to Agent-Based Financial Markets", Quantitative Finance, 1, 254-261.

Lettau, M. (1997) " Explaining the facts with adaptive agents: The case of mutual fund flows," Journal of Economic Dynamic and Control, 21, 1117-1147.

Lucas, Robert E., Jr. (1972) "Expectations And the Neutrality Of Money," Journal of Economic Theory, v4(2), 103-124.

Miller, E. M., (1977) "Risk, uncertainty, and divergence of opinion", Journal of Finance 32, 1151-1168.

Plott, C. R. and S. Sunder. (1982) "Efficiency of Experimental Security Markets With Insider Information: An Application Of Rational-Expectations Models," Journal of Political Economy, v90(4), 663698.

Theissen, Erik. (2000) "Market Structure, Informational Efficiency And Liquidity: An Experimental Comparison Of Auction And Dealer Markets," Journal of Financial Markets, v3(4,Nov), 333-363.

Yang, J. (2002) "The Efficiency of an Artificial Double Auction Stock Market with Neural Learning Agents." En Evolutionary Computation in Economics and Finance, editado por S.H. Chen, 79-98. SpringerVerlag.

\section{Acknowledgements}

Mikel Tapia acknowledges financial support from Ministerio de Ciencia y Tecnología grant BEC2002-00279, European Community's Human Potential Programme under contract HPRN-CT-2002-00232, MICFINMA and Fundacion Ramon Areces Research Grant. Javier Gil-Bazo and David Moreno acknowledge financial support from Ministerio de Ciencia y Tecnología grant SEJ2004-01688/ECON. 